\title{
OPEN Antifungal and anti-inflammatory potential of the endangered aromatic plant Thymus albicans
}

\author{
Mariana Roxo ${ }^{1}$, Mónica Zuzarte ${ }^{2,3,4 凶}$, Maria José Gonçalves $s^{5,6}$, Jorge M. Alves-Silva ${ }^{2,3,4,5}$, \\ Carlos Cavaleiro ${ }^{5,6}$, Maria Teresa $\mathrm{Cruz}^{3,5,7}$ \& Lígia Salgueiro ${ }^{5,6}$
}

Thymus albicans is an endemic species of the Iberian Peninsula with a vulnerable conservation status. In an attempt to contribute to the valorization of this species, the present study brings new insights on the antifungal and anti-inflammatory mechanism of action of $T$. albicans essential oil. The antifungal activity of the oil and its major compounds was assessed for the first time against standard and clinically isolated strains of yeasts and filamentous fungi. The effect on the two major virulence factors of Candida albicans (germ tube formation and biofilm disruption) was considered in more detail. At $0.08 \mu \mathrm{L} / \mathrm{mL}$, the oil inhibited C. albicans germ tube formation by more than $40 \%$ and decreased biofilm biomass at MIC values, thus pointing out its antivirulent potential. The anti-inflammatory activity of the essential oil was investigated on LPS-stimulated mouse macrophages (RAW 264.7) by evaluating the levels of several pro-inflammatory mediators, namely nitric oxide (NO), inducible nitric oxide synthase (iNOS) and cyclooxygenase-2 (COX-2). T. albicans oil reduced the production of nitrites, a NO derived sub-product, at non-cytotoxic concentrations of 0.32 and $0.64 \mu \mathrm{L} / \mathrm{mL}$, by 27 and $41 \%$, respectively. In addition, the iNOS protein levels of essential oil pre-treated cells were reduced by $14 \%$. Overall, the high essential oil yield of $T$. albicans as well as its bioactive effects at concentrations without cytotoxicity, encourage further studies on the potential pharmacological applications of this species. Furthermore, these results raise awareness for the need to preserve endangered species that may hold relevant medicinal value.

Thyme species are among the most important medicinal and aromatic crops in non-tropical environments ${ }^{1}$. The medicinal and non-medicinal uses of these plants are mainly related to their volatile extracts. Several Thymus spp. extracts are widely used for the treatment of gastrointestinal, respiratory and skin disorders, and their use is regulated by some entities and agencies, such as the European Medicines Agency ${ }^{2}$, European Scientific Cooperative on Phytotherapy ${ }^{3}$, German Commission E and World Health Organization ${ }^{4,5}$.

Food and flavour industries take advantage of the aromatic and antiseptic properties of thyme essential oils applying them in the preservation of food products and in the production of cosmetics and toiletries ${ }^{6}$. Moreover, due to its aromatic characteristics, thyme is a daily used culinary herb all over the world.

Thymus albicans Hoffm. and Link, popularly known in Portugal as tomilho-alvadio [syn. Origanum albicans (Hoffmans. and Link) Kuntze; Thymus mastichina var. micranthus Boiss.; Thymus tomentosus var. virescens Coss.; Thymus virescens (Coss.) Pau $]^{7}$ is an endemic species to the coastal area of the south-west Iberian Peninsula currently listed as vulnerable (meaning at high risk of extinction) by the IUCN Red List of Threatened Species ${ }^{8}$. It can only be found in the region of Algarve in Portugal, and in the provinces of Sevilla and Cádiz in Spain, being presently distributed in disperse and severely fragmented populations with a decreasing trend ${ }^{9}$. The main threats are related to the pressure exerted by mass tourism, agriculture and aquaculture practices.

Thymus albicans belongs to Sect. Mastichina, together with Thymus mastichina (L.) L. subsp. mastichina and Thymus mastichina subsp. donyanae R. Morales ${ }^{10}$. The aerial flowering parts of the plant are traditionally

\footnotetext{
${ }^{1}$ Institute of Pharmacy and Molecular Biotechnology (IPMB), Heidelberg University, Heidelberg, Germany. ${ }^{2}$ Faculty of Medicine, Coimbra Institute for Clinical and Biomedical Research (iCBR), University of Coimbra, Coimbra, Portugal. ${ }^{3}$ Centre for Innovative Biomedicine and Biotechnology (CIBB), University of Coimbra, Coimbra, Portugal. ${ }^{4}$ Clinical Academic Centre of Coimbra (CACC), Coimbra, Portugal. ${ }^{5}$ Faculty of Pharmacy of the University of Coimbra, University of Coimbra, Coimbra, Portugal. ${ }^{6}$ Chemical Process Engineering and Forest Products Research Centre (CIEPQPF), Department of Chemical Engineering, Faculty of Sciences and Technology, University of Coimbra, Coimbra, Portugal. ${ }^{7}$ Center for Neuroscience and Cell Biology (CNC), Coimbra, Portugal. ${ }^{\square}$ email: mzuzarte@uc.pt
} 
used for the same purposes of T. mastichina subsp. mastichina, mainly for the treatment of oral and pharyngeal inflammation and dermatitis ${ }^{11}$. Additionally, there is ethnopharmacological evidence of its use as a stomach tonic in Spain ${ }^{12}$.

Thymus mastichina is one of the most industrially relevant thyme species, currently employed in the production of cleaning products, perfumes, fragrances, soaps and other cosmetics ${ }^{13,14}$. It is widely cultivated in Portugal and Spain, and has an ISO standard (4728:2003) specifying the quality parameters of the essential oil for industrial and commercial uses ${ }^{15}$. Several pharmacological activities have been reported for T. mastichina essential oil, including antimicrobial activity ${ }^{16-19}$, anti-inflammatory potential ${ }^{20,21}$, antioxidant activity ${ }^{22-24}$ and cytotoxicity against cancer cell lines ${ }^{25-27}$. Due to the similarities between the chemical profile of T. mastichina and T. albicans essential oils, it seems reasonable to assume that both species might possess similar bioactive properties. This assumption is in part corroborated by previous studies showing the antibacterial activity of $T$. albicans essential oil against Gram-positive bacteria ${ }^{28}$, its antioxidant activity ${ }^{29,30}$, its capacity to scavenge nitric oxide and to inhibit the activity of lipoxygenase in vitro, both commonly used as markers of anti-inflammatory potential $^{21}$. As far as we know, those are the only studies on the bioactive potential of T. albicans essential oil. More studies are needed to further confirm the reported effects and to explore new bioactivities.

In this regard, the present study aimed to investigate the chemical profile, and the antifungal and antiinflammatory activities of Thymus albicans essential oil from Portugal and its major compounds, concomitantly highlighting the mechanisms of action underlying these effects. These bioactivities were selected taking into account their current relevance in the clinic. In fact, invasive fungal infections are an increasingly important global health burden accounting for 1.66 million deaths every year ${ }^{31}$. While these mainly affect immunocompromised individuals, superficial fungal infections are reported to affect between 20 and $25 \%$ of the world's population, including immunocompetent individuals ${ }^{32}$. Treatment failure and high relapse rates are mainly correlated with the extensive use of a limited number of non-selective antifungal drugs (e.g. fluconazole, amphotericin B and terbinafine) which leads to off-target toxicity and to the emergence of resistance among the main etiologic agents $^{33}$. Chronic inflammation is another factor that contributes to the successful colonization of the host tissues by pathogenic fungi and may impede disease eradication ${ }^{34}$. Taken together, these facts justify the urgency for therapeutic alternatives, preferentially combining selective antifungal and anti-inflammatory activities.

\section{Results and discussion}

Essential oil composition. Prior to this study, several essential oils from T. albicans plants collected in different regions of Algarve (Portugal) were chemically characterized, revealing chemical variability regarding the four major compounds 1,8-cineole (29-43\%), linalool (5-25\%), a-terpineol (4.5-9.8\%) and borneol (2.2-8.0\%). The most predominant chemical profile was characterized by high contents of 1,8-cineole and linalool. Therefore, for the present study we selected the sample that better represented the chemical profile of the essential oils from Portuguese T. albicans. This sample was obtained from populations with the same chemical profile growing in Foz de Almargem coastal lagoon in Algarve. The chemical characterization of the obtained essential oil is shown in Table 1.

Oxygen containing monoterpenes represented the major fraction of the oil (85.5\%). The major compounds identified were 1,8-cineole (40.5\%) and linalool (25.0\%), followed by borneol (6.4\%) and $\alpha$-terpineol (4.5\%). The Total Ion Current (TIC) chromatogram, processed using HP Enhanced ChemStation software, is shown in Fig. 1. Our results are in accordance with the works of Morales Valverde ${ }^{10}$ and Salgueiro, et al ${ }^{35}$ that pointed out 1,8-cineole as the major compound of T. albicans essential oil from Portugal followed by linalool. Miguel, et al. ${ }^{36}$ studied the oils obtained from leaves and from flowers, distinguishing the chemotypes 1,8-cineole and 1,8-cineole/linalool.

Thymus albicans essential oil, in the present study, was obtained from the flowering aerial parts with a yield of $2.4 \%(\mathrm{v} / \mathrm{w})$. Our results are in agreement with the study of Aazza, et al. ${ }^{21}$ reporting a yield of $2.2 \%$. This yield is quite relevant since it is higher than that obtained with industrially relevant species, such as T. vulgaris, T. zygis and T. mastichina, thus highlighting the industrial potential of T. albicans.

Fungal growth (MIC and MLC). As far as it is known, this is the first report on the antifungal effect of $T$. albicans essential oil. The oil showed some degree of inhibition against all Candida, Cryptococcus neoformans, dermatophytes and Aspergillus strains tested (Table 2), thus showing a broad-spectrum antifungal effect. Moreover, for the majority of yeast and all dermatophyte strains, MIC values were similar to MLC ones, pointing out a fungicidal effect of the oil. The highest antifungal activity was observed against Trichophyton rubrum CECT 2794 and Epidermophyton floccosum FF9 (MIC and MLC of $0.64 \mu \mathrm{L} / \mathrm{mL}$ ).

Other essential oils with high amounts of 1,8-cineole, such as the ones isolated from Salvia fruticosa, Thymus capitellatus and Thymus mastichina, were previously shown to exert antifungal activity against several fungal species $^{16,37,38}$.

Regarding the antifungal activity of T. albicans major compounds, 1,8-cineole, linalool, borneol and a-terpineol, only the later showed a slightly stronger effect than the essential oil. Among the strains tested, $C$. parapsilosis ATCC 90018, Cryptococcus neoformans CECT 1078 and Aspergillus strains were the most susceptible to $\alpha$-terpineol with MIC values ranging from 0.32 to $1.25 \mu \mathrm{L} / \mathrm{mL}$. Also, Hammer, et al..$^{39}$ demonstrated that a-terpineol was more active than 1,8-cineole against some of the fungi species tested, namely C. albicans, $C$. parapsilosis, E. floccosum, M. canis, T. mentagrophytes var. interdigitale, T. rubrum, A. niger, A. fumigatus and A. flavus. Although 1,8-cineole had a weak activity, several studies reported synergistic effects of this compound with other monoterpenes ${ }^{40}$. Moreover, this compound has also shown synergistic effects with chlorhexidine, a commonly used antiseptic ${ }^{41,42}$. 


\begin{tabular}{|c|c|c|c|}
\hline $\mathbf{R I}^{\mathbf{a}}$ & $\mathbf{R I}^{\mathrm{P}}$ & Compounds $^{a}$ & $\%$ \\
\hline 922 & 1030 & a-Thujene & 0.2 \\
\hline 930 & 1030 & a-Pinene & 1.7 \\
\hline 943 & 1073 & Camphene & 2.3 \\
\hline 964 & 1128 & Sabinene & 1.1 \\
\hline 970 & 1118 & $\beta$-Pinene & 1.9 \\
\hline 980 & 1161 & Myrcene & 0.7 \\
\hline 1006 & 1185 & a-Terpinene & 0.4 \\
\hline 1013 & 1272 & $p$-Cymene & 0.1 \\
\hline 1020 & 1206 & Limonene & 0.6 \\
\hline 1020 & 1212 & 1,8-Cineole & 40.5 \\
\hline 1035 & 1250 & trans- $\beta$-Ocimene & 0.2 \\
\hline 1047 & 1250 & $\gamma$-Terpinene & 0.3 \\
\hline 1050 & 1459 & trans-Sabinene hydrate & 0.1 \\
\hline 1081 & 1543 & Linalool & 25.0 \\
\hline 1115 & 1516 & Camphor & 3.4 \\
\hline 1129 & 1668 & trans-Verbenol & 0.1 \\
\hline 1142 & 1667 & $\delta$-Terpineol & 3.0 \\
\hline 1142 & 1693 & Borneol & 6.4 \\
\hline 1158 & 1595 & Terpinen-4-ol & 1.4 \\
\hline 1166 & 1692 & a-Terpineol & 4.5 \\
\hline 1178 & 1780 & Myrtenol & 0.1 \\
\hline 1210 & 1764 & Citronellol & 0.2 \\
\hline 1233 & 1842 & Geraniol & 0.4 \\
\hline 1266 & 1574 & Bornyl acetate & 0.3 \\
\hline 1359 & 1755 & Geranyl acetate & 0.1 \\
\hline 1382 & 1585 & $\beta$-Elemene & 0.3 \\
\hline 1411 & 1590 & trans- $\beta$-Caryophyllene & 0.5 \\
\hline 1498 & 1751 & $\gamma$-Cadinene & 0.1 \\
\hline 1526 & 2070 & Elemol & 0.1 \\
\hline 1557 & 1968 & Caryophyllene oxide & 0.4 \\
\hline 1569 & 2072 & Viridiflorol & 0.2 \\
\hline 1579 & 2025 & Ledol & 0.1 \\
\hline 1615 & 2153 & T-Cadinol & $t$ \\
\hline 1628 & 2218 & a-Cadinol & $t$ \\
\hline \multirow[t]{6}{*}{1628} & 2208 & a-Eudesmol & $\mathrm{t}$ \\
\hline & & Monoterpene hydrocarbons & 9.5 \\
\hline & & Oxygen containing monoterpenes & 85.5 \\
\hline & & Sesquiterpene hydrocarbons & 0.9 \\
\hline & & Oxygen containing sesquiterpenes & 0.9 \\
\hline & & Total & 96.8 \\
\hline
\end{tabular}

Table 1. Composition of the essential oil of Thymus albicans. $\mathrm{RI}^{\mathrm{a}}$, retention indices on the SPB-1 column

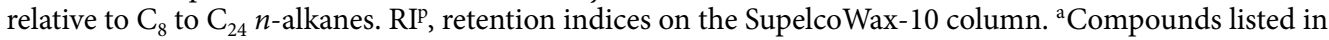
order of their elution on the SPB-1 column; $t$, traces $(\leq 0.05 \%)$.

Candida albicans virulence factors. Among Candida species, C. albicans is the main etiological agent of candidiasis and one of the main causes of hospital-acquired infections ${ }^{43}$. The pathogenicity of C. albicans is associated with two major virulence factors: germ tube and biofilm formation. The germ tube (filamentation) confers increased resistance to phagocytosis and allows the penetration into deeper layers of the mucosa leading to invasive infections ${ }^{44}$. Biofilms, formed on both implanted medical devices and host tissues, potentiate C. albicans dissemination and increase its resistance to conventional drugs ${ }^{45}$. They act as reservoirs of multi-resistant yeast cells, which upon filamentation trigger resistant systemic infections. Despite the major role of these virulence factors in the pathogenesis of invasive Candida infections, to date, no-specific germ tube and biofilm antifungal drugs are available.

Candida albicans germ tube formation. In our study, T. albicans essential oil was able to strongly inhibit the germ tube formation of C. albicans at concentrations much lower than the respective MIC. At $0.08 \mu \mathrm{L} / \mathrm{mL}$ the oil inhibited germ tube formation by $40.5 \%$ and at $0.32 \mu \mathrm{L} / \mathrm{mL}$ a $96.3 \%$ inhibition was attained (Fig. 2). These 


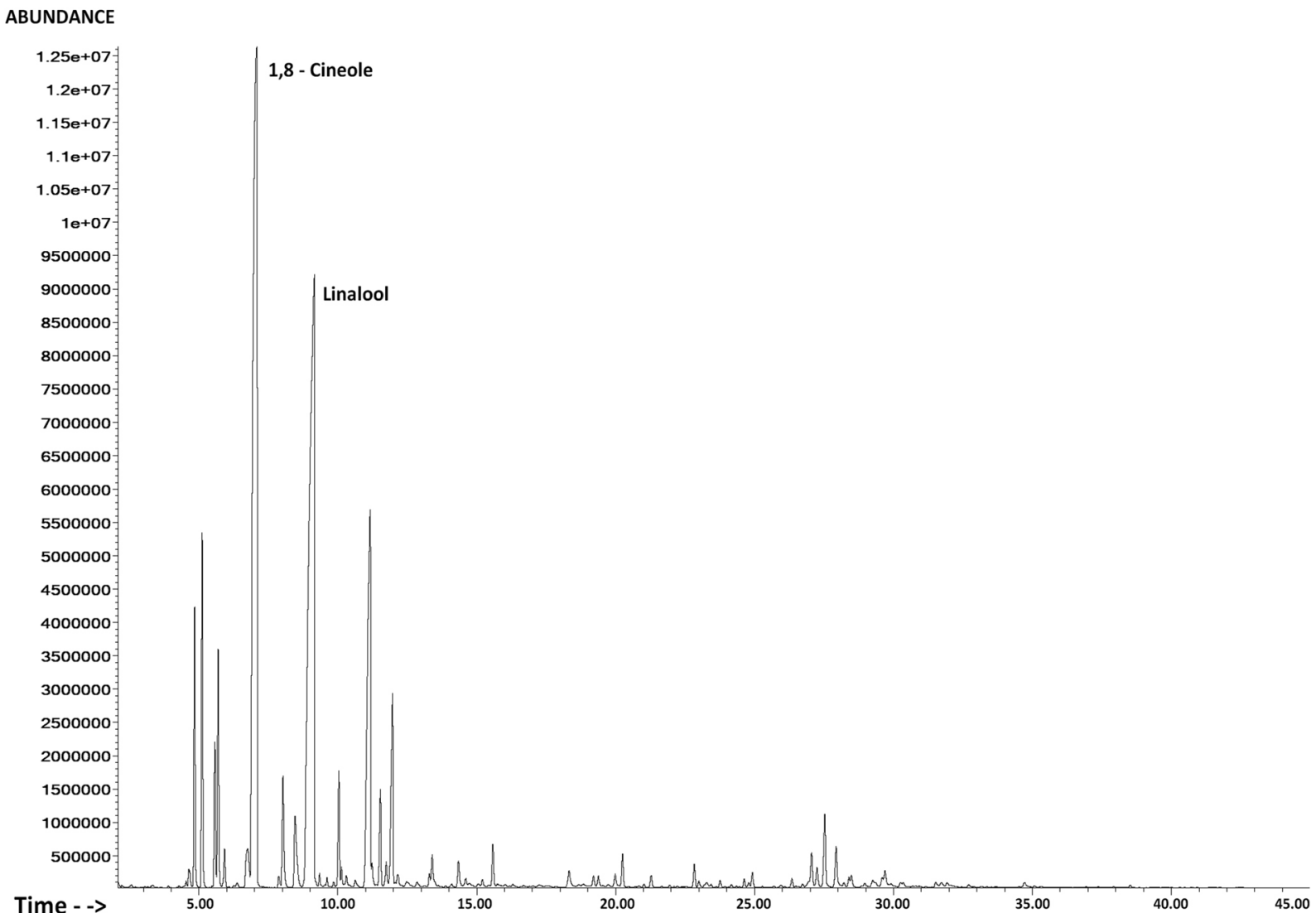

Figure 1. Total ion current chromatogram of the essential oil of Thymus albicans.

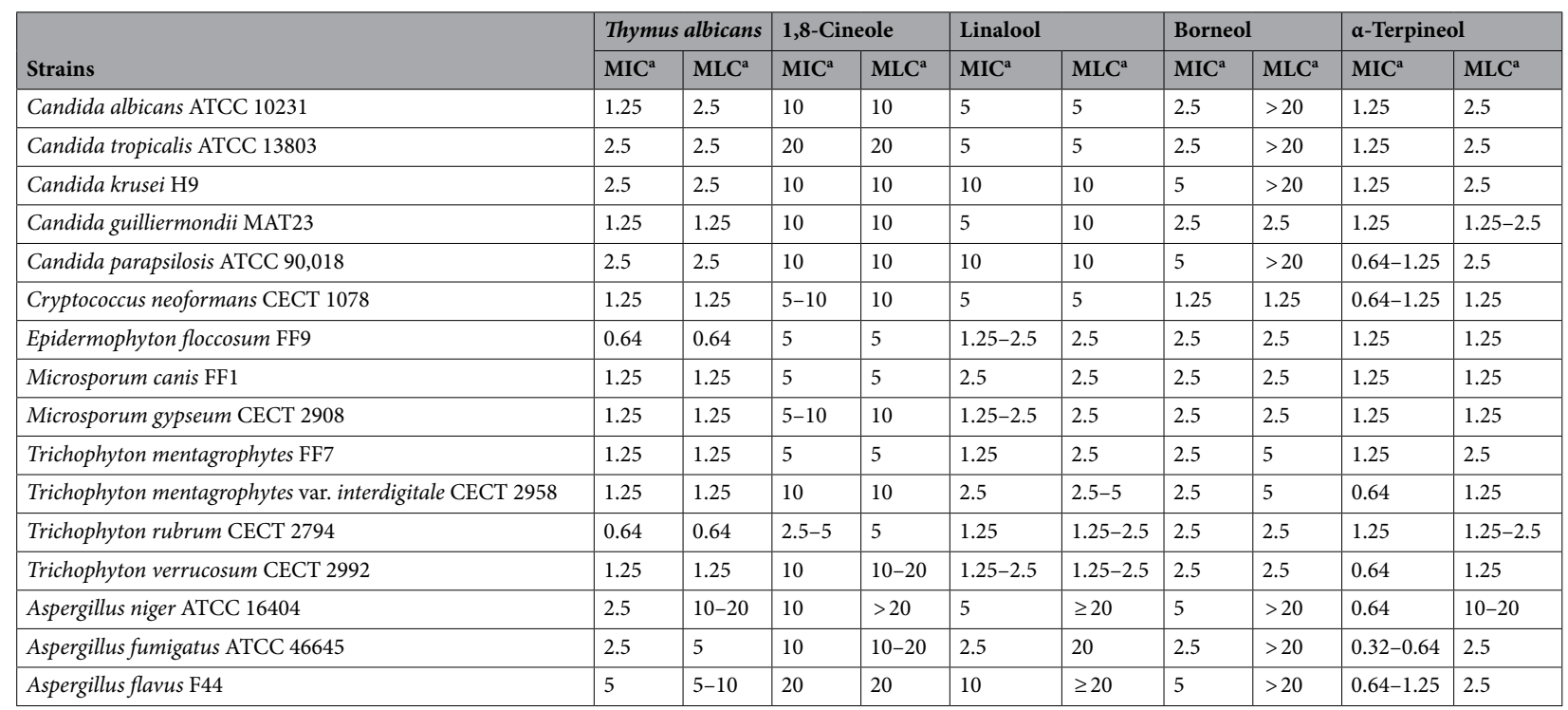

Table 2. Antifungal activity (MIC and MLC) of Thymus albicans essential oil and its major compounds (1,8-cineole, linalool, borneol and a-terpineol) against collection type and clinical strains of Candida, Cryptococcus neoformans, dermatophytes and Aspergillus. ${ }^{\mathrm{a}} \mathrm{MIC}$ and MLC determined by macrodilution method and expressed as $\mu \mathrm{L} / \mathrm{mL}$. 


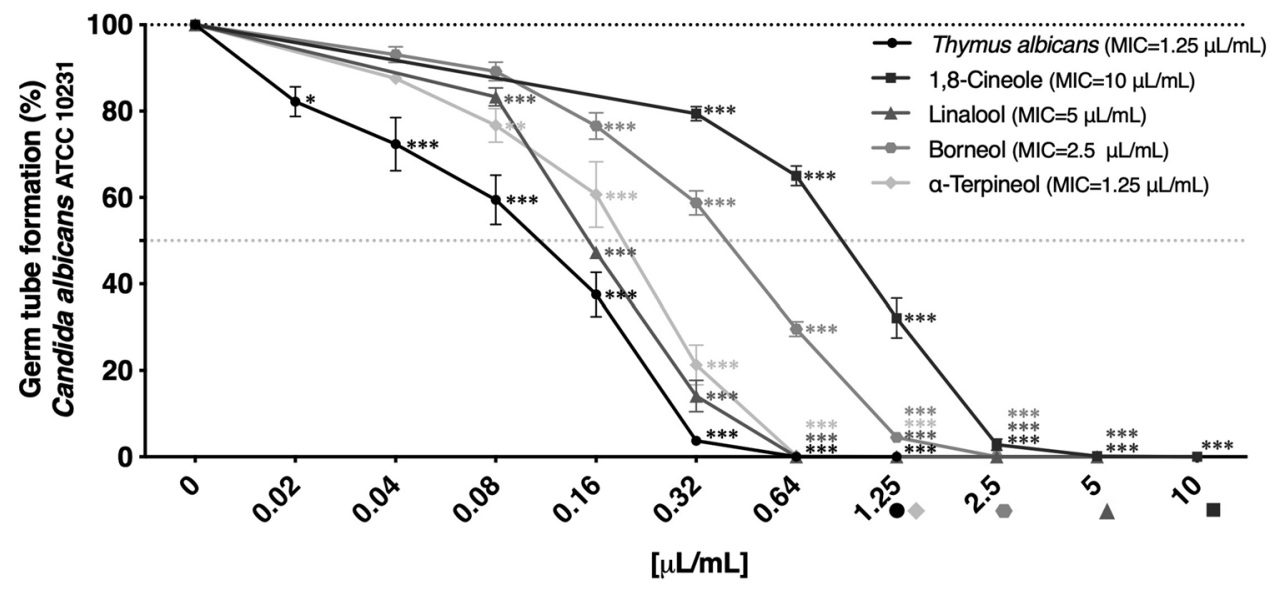

Figure 2. Germ tube formation in Candida albicans ATCC 10231 treated with sub-inhibitory concentrationsranging from MIC to MIC/64-of Thymus albicans essential oil and its main compounds (1,8-cineole, linalool, borneol and $\alpha$-terpineol). The values are presented as percentage of control (oil-free samples with $1 \%$ DMSO $(\mathrm{v} / \mathrm{v})) \pm$ SEM of at least three independent experiments performed in duplicate. Statistical differences were calculated by one-way ANOVA followed by Dunnett's post hoc test $\left({ }^{*} p<0.05,{ }^{* *} p<0.01,{ }^{* *} p<0.001\right)$.

A.

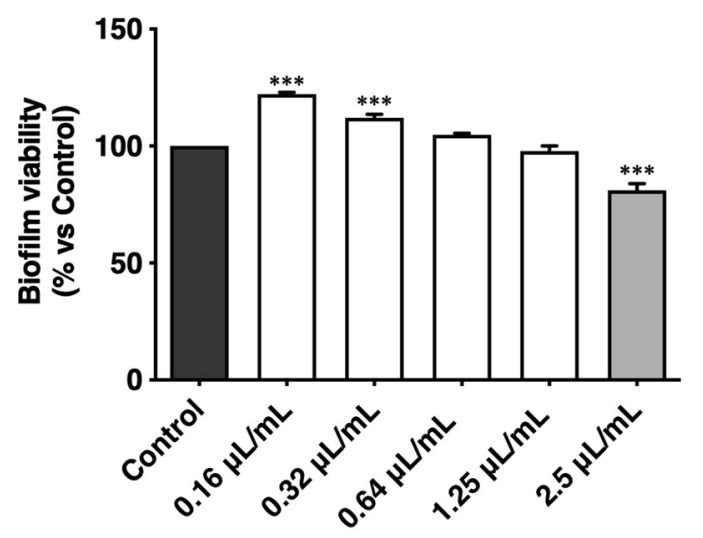

B.

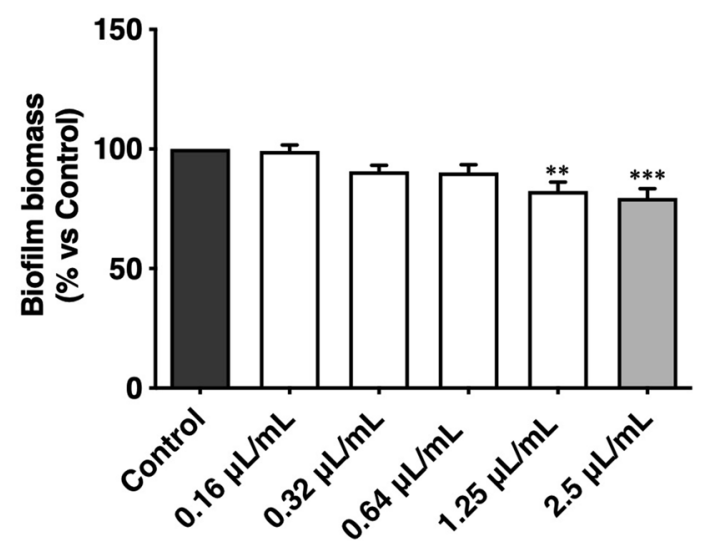

Figure 3. Influence of Thymus albicans essential oil on Candida albicans ATCC 10231 biofilm viability (A) and effect on biofilm biomass after $24 \mathrm{~h}$ (B). Each value represents the mean \pm SEM of at least three independent experiments performed in duplicate. Statistical differences were calculated by one-way ANOVA followed by Dunnett's post hoc test $\left({ }^{* *} p<0.01,{ }^{* * *} p<0.001\right)$. The grey bar represents the minimum lethal concentration (MLC) of Thymus albicans essential oil against Candida albicans ATCC 10231.

results are quite interesting since fluconazole, a conventional antifungal drug widely used in the clinic, despite inhibiting fungal growth at very low concentrations, is ineffective in decreasing germ tube formation. Indeed, even at concentrations up to $200 \mu \mathrm{g} / \mathrm{mL}$ the percentage of inhibition did not exceed $10 \%$ (Figure S1). Conversely, T. albicans essential oil was able to strongly reduce C. albicans germ tube formation at concentrations as low as $0.08 \mu \mathrm{L} / \mathrm{mL}$.

Regarding the major compounds tested, only linalool could completely inhibit germ tube formation at subMIC concentrations $(0.64 \mu \mathrm{L} / \mathrm{mL})$. Hsu et al. ${ }^{46}$ and Zore et al. ${ }^{47}$ also reported the ability of linalool to decrease C. albicans germ tube formation at sub-inhibitory concentrations. The results obtained for 1,8-cineole are consistent with those reported by Pina-Vaz et al. ${ }^{16}$. Moreover, in the same study, phenolic thyme essential oils from T. vulgaris and T. zygis were less effective than T. albicans in inhibiting germ tube formation, although both oils showed better antifungal activity (lower MIC values) against C. albicans.

Disruption of preformed biofilms in Candida albicans. Besides germ tube formation, the pathogenicity of C. albicans is also associated with biofilm formation. In the present study, T. albicans essential oil was assessed for its capacity to decrease biofilm mass and viability (Fig. 3). At MIC values, the oil decreased biofilm mass, while fluconazole had no effect. 
A.

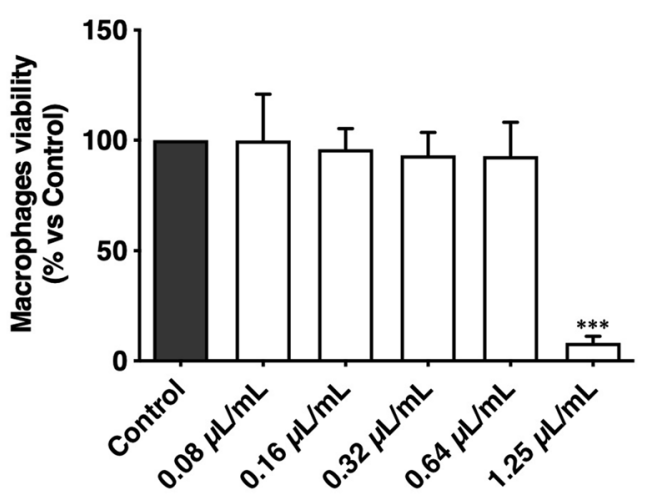

B.

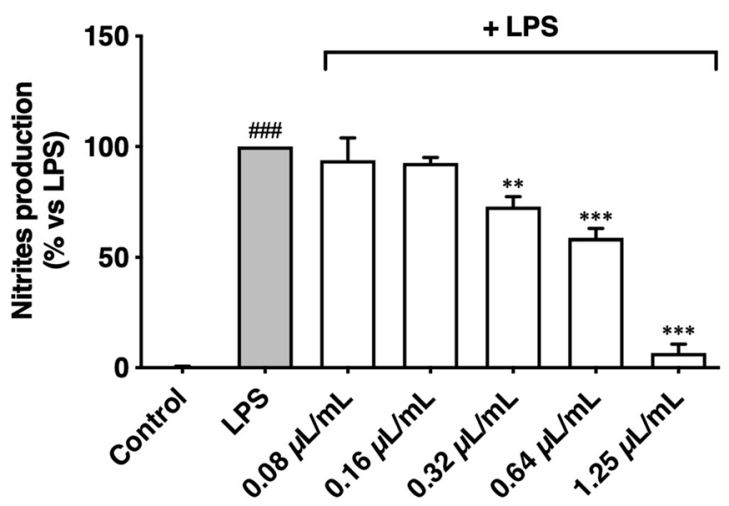

Figure 4. Effect of Thymus albicans essential oil on macrophages viability (A) and nitrites production (B). Cell viability is expressed as a percentage of MTT reduction in comparison to control cells (100\% viability). Nitrite production is expressed as a percentage of nitrite production in comparison to cells stimulated with LPS alone (100\% nitrite production). Each value represents the mean \pm SEM from three experiments, performed in duplicate. Statistical differences between groups were calculated by one-way ANOVA followed by Dunnett's post hoc test (\#\#\#p<0.001, compared to control (B); ${ }^{* *} p<0.01,{ }^{* * *} p<0.001$ compared to control (A) and to LPS (B)).

The main compound of T. albicans essential oil, 1,8-cineole, was shown to inhibit C. albicans biofilms at higher concentrations than the oil ${ }^{41}$. Also, other major compounds, namely linalool, borneol and $\alpha$-terpineol were previously reported to disrupt C. albicans biofilm formation ${ }^{46,48,49}$.

Germ tube formation and biofilm integrity in C. albicans are important virulence factors that allow the transition from a superficial mycosis to a systemic infection. Overall, our results show that T. albicans essential oil presents antivirulent potential against $C$. albicans since it was able to inhibit both of these features. The possibility of targeting virulence factors at non-growth inhibitory concentrations is a promising therapeutic strategy, particularly because it may reduce the toxicity of antifungal therapy simultaneously reducing not only the selective pressure for the emergence of resistance among pathogenic fungi but also the impact on the host's natural microbiota ${ }^{44}$.

Anti-inflammatory activity. LPS-stimulated mouse macrophages (RAW 264.7) were used as an in vitro model of acute inflammation. Briefly, LPS, a Toll-like receptor 4 agonist and a component of the outer membrane of Gram-negative bacteria, acts upstream of the NF- $\mathrm{kB}$ signaling pathway inducing the phosphorylation and degradation of its inhibitory protein $\kappa \mathrm{B}(\mathrm{I} \kappa \mathrm{B})$. Once released from inhibition, NF- $\kappa \mathrm{B}$ translocates into the nucleus activating the transcription of genes coding for the inducible form of nitric oxide synthase (iNOS) and cyclooxygenase-2 (COX-2), two pro-inflammatory enzymes, among others. iNOS catalyzes the synthesis of NO through oxidation of L-arginine and COX-2 the conversion of arachidonic acid to prostaglandin E2 (PGE2) ${ }^{50}$.

In our study, the levels of NO stable metabolites (nitrites) before and after T. albicans oil treatment were measured by the colorimetric Griess reaction and used as a parameter to determine the anti-inflammatory potential of the essential oil.

Our results demonstrate that T. albicans oil was able to inhibit nitrites production by LPS-stimulated macrophages in a dose-dependent manner. Importantly, a significant reduction by 27.16 and $41.32 \%$, was observed at the non-cytotoxic concentrations of 0.32 and $0.64 \mu \mathrm{L} / \mathrm{mL}$, respectively, in comparison with the LPS stimuli (Fig. 4). In an analogous experiment, Zuzarte et al. ${ }^{51}$ evaluated the effect of 1,8 -cineole on the same parameter, demonstrating that it also inhibited the production of nitrites, however at higher concentrations $(2.25 \mu \mathrm{L} / \mathrm{mL})$. This indicates that other compounds may contribute to the anti-inflammatory activity of T. albicans oil.

Mechanism of action: scavenging capacity or gene expression regulation? To clarify whether the lower levels of nitrites observed after T. albicans essential oil treatment were due to its direct scavenging potential, a reaction between a NO donor (SNAP) and different concentrations of the oil was performed. Since T. albicans essential oil failed to scavenge NO (Fig. 5), we could exclude this hypothesis to justify the reduction of nitrite levels in LPS-stimulated macrophages. In the study of Aazza, et al. ${ }^{21}$, T. albicans essential oil was shown to scavenge NO in vitro, however at much higher concentrations than those tested in our study.

Another mechanism by which T. albicans essential oil could reduce the nitrite levels is the modulation of genes coding for key enzymes along the inflammatory pathway, namely iNOS and COX-2. Our results show that the expression of both enzymes by LPS-stimulated macrophages was significantly higher $(p<0.001)$ in comparison to the LPS-free control (Fig. 6), demonstrating the ability of LPS to induce the expression of these enzymes in our inflammatory-like model. Cells treated only with essential oils revealed neglectable levels of iNOS and COX-2 expression, ruling out possible pro-inflammatory effects of the oil.

At $0.64 \mu \mathrm{L} / \mathrm{mL}$, T. albicans essential oil inhibited by $13.64 \%$ iNOS expression in comparison to the LPS stimulus $(p<0.01)$. This slight decrease of iNOS protein levels in LPS-stimulated macrophages pre-treated with T. albicans essential oil does not reflect the significant NO reduction evaluated through Griess reaction. It seems 


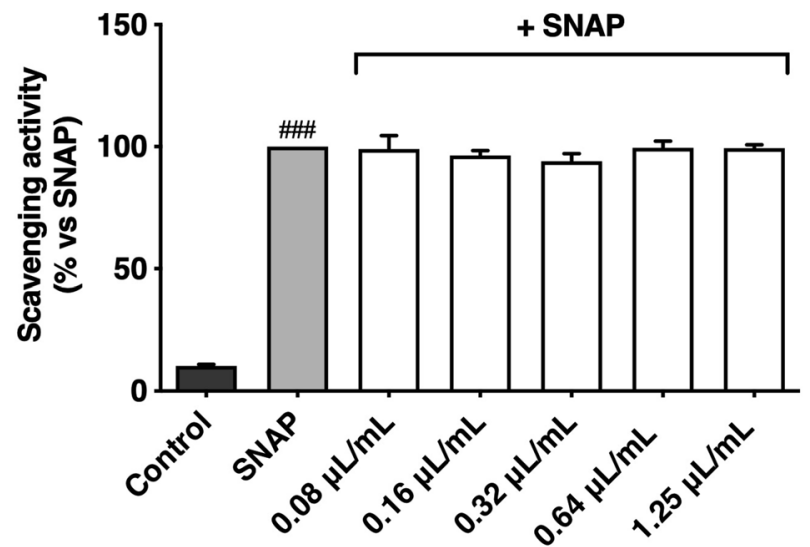

Figure 5. NO scavenging potential of Thymus albicans essential oil. Different concentrations of essential oil $(0.08-1.25 \mu \mathrm{L} / \mathrm{mL})$ were incubated with SNAP $(300 \mu \mathrm{M})$ in culture medium for $3 \mathrm{~h}$. Results are expressed as a percentage of NO release triggered by SNAP. Each value represents the mean \pm SEM of three independent assays, performed in duplicate. Statistical differences were calculated by one-way ANOVA followed by Dunnett's post hoc test (\#\# $p<0.001$, compared to control).

LPS $1 \mu \mathrm{g} / \mathrm{mL}$

Thymus albicans
$+$

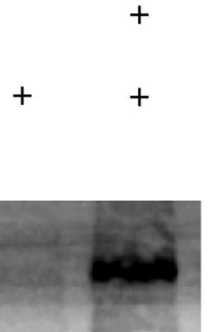

Tubulin $55 \mathrm{kDa}$

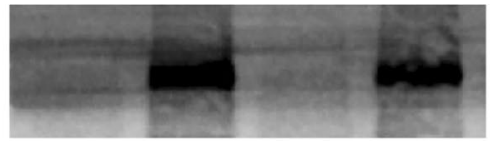

iNOS

$135 \mathrm{kDa}$

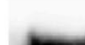

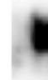
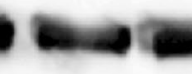

.
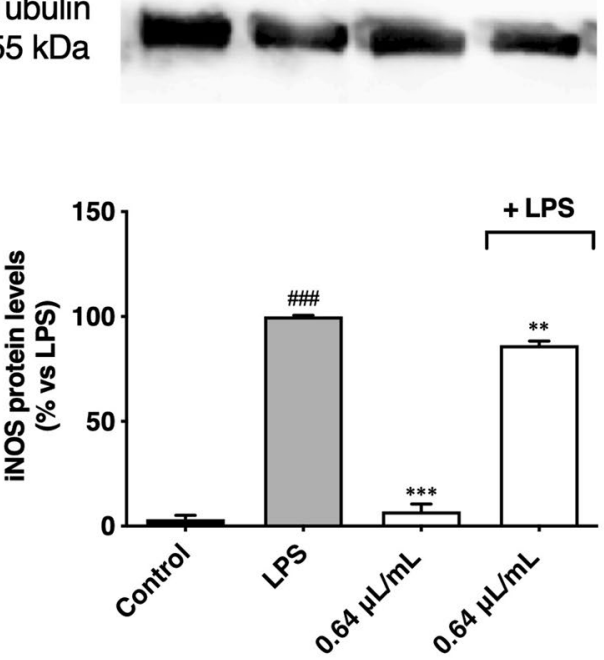

cox-2

$70 \mathrm{kDa}$

Tubulin $55 \mathrm{kDa}$

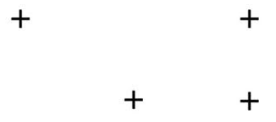


The anti-inflammatory activity of T. albicans main compounds is broadly reported in both pre-clinical and clinical studies. Accordingly, in a clinical study conducted by Juergens et al. ${ }^{52}, 1,8$-cineole revealed anti-inflammatory activity in patients with severe asthma. Using human cell lines, Greiner et al. ${ }^{53}$ demonstrated the ability of 1,8 -cineole to attenuate the activity of NF- $\kappa \mathrm{B}$, thus decreasing its nuclear translocation and consequently reducing the expression of its target genes coding for pro-inflammatory mediators. Nogueira et al. ${ }^{54}$ showed that it modulates the production of pro-inflammatory cytokines by LPS-stimulated macrophages by interfering with NF- $\kappa$ B, p38 or ERK/MAPK pathways. Peana et al. ${ }^{55}$ demonstrated the capacity of linalool to reduce NO production in LPS-stimulated macrophages, although it failed to inhibit iNOS expression. The authors suggested that linalool could possibly act as a scavenger of NO or as an inhibitor of iNOS activity.

Huo et al. ${ }^{56}$ also showed the anti-inflammatory activity of linalool using in vitro and in vivo models. Linalool inhibited NF-kB and MAPK activation in LPS-stimulated macrophages and protected mice against LPS-induced acute lung injury by reducing the production of TNF- $\alpha$ and IL-6. Borneol was shown to decrease the expression of cytokines (IL-6 and IL-8) in human gingival fibroblasts ${ }^{57}$. These studies confirm the contribution of 1,8-cineole, linalool, borneol and $\alpha$-terpineol to the anti-inflammatory activity of T. albicans essential oil.

Other thyme essential oils rich in 1,8-cineole were previously reported to have anti-inflammatory potential, namely T. mastichina, which was shown to inhibit lipoxygenase activity ${ }^{21,29}$, T. hyemalis, which reduced the secretion of pro-inflammatory cytokines (TNF- $\alpha$, IL1 $\beta$, and IL-6) in an inflammatory model of human macrophages stimulated with $\mathrm{Cu}^{2+}$-oxidized LDLs ${ }^{58}$, and T. camphoratus (chemotype 1,8-cineole/borneol) that inhibited both iNOS and COX-2 in the same model of LPS-stimulated macrophages used in this study ${ }^{59}$.

\section{Conclusion}

Thymus albicans essential oil showed a broad spectrum antifungal activity. The oil was able to inhibit germ tube formation and biofilm integrity in Candida albicans, which are two key virulent factors of this highly prevalent etiologic agent of topical and invasive candidiasis in humans. In addition, at concentrations devoid of toxicity, Thymus albicans essential oil was able to reduce the production of the pro-inflammatory mediator NO. This anti-inflammatory effect was shown to be partly related to the reduction of iNOS levels.

The combination of antifungal and anti-inflammatory effects together with the high essential oil yield (2.4\%) and absence of cytotoxicity at bioactive concentrations demonstrate the therapeutic potential of Thymus albicans, an endangered Iberian species. Moreover, the results obtained in the present study corroborate the traditional use of Thymus species as antimicrobial and anti-inflammatory agents.

Also, T. albicans revealed higher essential oil yield than other widely marketed thyme species like Thymus vulgaris L., Thymus zygis L. and T. mastichina. It is important to underline that although T. albicans and T. mastichina are both species of the Mastichina section with high content of 1,8-cineole, only T. mastichina oil has industrial relevance, proven by the established ISO 4728:2003 standard ${ }^{15}$. Indeed, the bioactivities herein reported confirm the potential of T. albicans essential oil paving the way for further studies on the pharmaceutical applications of this species, which might contribute to improve its conservation status.

\section{Material and methods}

Plant material. Flowering parts of Thymus albicans Hoffmanns. and Link were collected at the same time in the area of Foz de Almargem coastal lagoon, Algarve, Portugal. All plants presented a similar stage of development. Voucher specimens were included in the Herbarium of the University of Coimbra (COI), with the accession number Moura 4796. Dr. Jorge Paiva, a taxonomist at the University of Coimbra, confirmed species authenticity and plant names were checked with https://www.theplantlist.org.

Essential oil isolation and analysis. The essential oils from the aerial parts of T. albicans plants were obtained by hydrodistillation for $3 \mathrm{~h}$, using a Clevenger-type apparatus ${ }^{60}$. Chemical analyses were carried out by both gas chromatography (GC-FID) and gas chromatography-mass spectroscopy (GC-MS) using fused silica capillary columns with two stationary phases (SPB-1 and SupelcoWax 10) as previously reported ${ }^{61}$.

The compounds were identified based on their GC retention indices on both columns and through their mass spectra. Retention indices, calculated by linear interpolation relative to the retention times of $\mathrm{C}_{8}-\mathrm{C}_{24} n$-alkanes (Eq. 1) ${ }^{62}$, were compared with those of authentic products included in the Faculty of Pharmacy of the University of Coimbra laboratory database and/or literature data ${ }^{63,64}$. Acquired mass spectra were compared with reference spectra from the laboratory database, Wiley/NIST library and literature data ${ }^{63,65}$. Relative amounts of individual components were calculated based on GC raw data areas without a response factor correction for flame ionization detection.

$$
I_{a}^{\varphi}=100 z+100\left[\frac{T_{(a)}-T_{(z)}}{T_{(z+1)}-T_{(z)}}\right]
$$

$I \varphi$, experimental retention indices of the analyte "a" in the stationary phase " $\varphi$ "; $z$, number of carbons of the $n$-alkane with the closest previous elution to " $a$ "; $T_{(z)}$, retention time of the $n$-alkane with the closest previous elution to " $a$ "; $T_{(z+1)}$, retention time of the $n$-alkane with the closest after elution to " $a$ "; $T_{(a)}$, Retention time of the analyte " $a$ ".

Pure and reference compounds. The following synthetic compounds were purchased: 1,8-cineole (extra pure, Merck, Darmstadt, Germany), linalool (pure, Fluka, Steinheim, Germany), borneol (pure, Fluka, Steinheim, Germany) and a-terpineol (pure, Extrasynthese, Genay, France). 
Fungal growth (MIC and MLC). The antifungal activity of T. albicans essential oil and its major compounds (1,8-cineole, linalool, borneol and $\alpha$-terpineol) was evaluated against two Candida strains isolated from recurrent cases of vulvovaginal and oral candidiasis (C. krusei H9, C. guilliermondii MAT23) and three type strains (C. albicans ATCC 10231, C. tropicalis ATCC 13803, C. parapsilosis ATCC 90018); a Cryptococcus neoformans type strain (C. neoformans CECT 1078); three clinical dermatophyte strains isolated from nails and skin (Epidermophyton floccosum FF9, Microsporum canis FF1, Trichophyton mentagrophytes FF7) and four type strains (M. gypseum CECT 2908, T. mentagrophytes var. interdigitale CECT 2958, T. rubrum CECT 2794, T. verrucosum CECT 2992); one Aspergillus clinical strain isolated from bronchial secretions (A. flavus F44) and two type strains (A. niger ATCC 16404, A. fumigatus ATCC 46645). The fungal isolates were stored on Sabouraud broth with $20 \%$ of glycerol at $-80^{\circ} \mathrm{C}$ and previously cultured on Sabouraud Dextrose Agar (SDA) or Potato Dextrose Agar (PDA) to ensure optimal growth characteristics and purity for the antifungal susceptibility testing.

Minimal Inhibitory Concentrations (MICs) and Minimal Lethal Concentrations (MLCs) were determined using the macrodilution method, according to Clinical and Laboratory Standards Institute guidelines for yeasts and filamentous fungi as described by Zuzarte et al. ${ }^{51}$.

Candida albicans virulence factors. Germ tube inhibition. Cell suspensions $\left(1.0 \pm 0.2 \times 10^{6} \mathrm{CFU} / \mathrm{mL}\right)$ from overnight SDA cultures were prepared in NYP medium [ $\mathrm{N}$-acetylglucosamine (Sigma-Aldrich, St. Louis, MO, USA; $10^{-3} \mathrm{~mol} / \mathrm{L}$ ), yeast nitrogen base (Difco, Detroit, MI, USA; $3.35 \mathrm{~g} / \mathrm{L}$ ), proline (Fluka; $1023 \mathrm{~mol} / \mathrm{L}$ ) and $\mathrm{NaCl}(4.5 \mathrm{~g} / \mathrm{L}), \mathrm{pH} 6.7 \pm 0.1$ ]. Serial two-fold essential oil dilutions were previously prepared in DMSO [maximum concentration of $1 \%(\mathrm{v} / \mathrm{v})]$, and added to the inoculum suspensions to obtain a range of test concentrations from MIC value to MIC/64 (1.25-0.02 $\mu \mathrm{L} / \mathrm{mL})$. Oil-free controls with and without DMSO were included. After $3 \mathrm{~h}$ of incubation in a static chamber at $37^{\circ} \mathrm{C}$, homogenized cell suspensions of each treatment were mounted onto a Neubauer chamber; 100 cells per replica were counted and visually scored, excluding gemulating cells. The percentage of filamentation was defined as the number of cells in which the size of the germ tube was equal or bigger than the blastopore's diameter.

Disruption of preformed biofilms. The effect of the T. albicans essential oil on the disruption of C. albicans ATCC 10231 preformed biofilm was investigated following the method described by Alves-Silva et al. ${ }^{66}$. Briefly, a cell suspension of C. albicans was prepared in Yeast Peptone Dextrose (YPD) broth (1\% yeast extract, $2 \%$ peptone, and $2 \%$ dextrose) and incubated for $24 \mathrm{~h}$ at $37^{\circ} \mathrm{C}$. A final suspension of $1 \times 10^{6} \mathrm{CFU} / \mathrm{mL}$ was added to 96 -well microtiter plates and incubated for $24 \mathrm{~h}$ at $37^{\circ} \mathrm{C}$, to form the biofilms. After three washing steps with PBS, the essential oils $(0.16-2.5 \mu \mathrm{L} / \mathrm{mL})$ prepared in RPMI were added and incubated for $24 \mathrm{~h}$ at $37^{\circ} \mathrm{C}$. Negative and positive controls were included using sterile and inoculated RPMI media, respectively.

Anti-inflammatory activity. Cell line and culture conditions. The mouse macrophage cell line, RAW 264.7 (ATCC-TIB-71) was cultured in Dulbecco's modified eagle medium (DMEM) (Invitrogen, California, USA) supplemented with $10 \%(\mathrm{v} / \mathrm{v})$ of non-inactivated fetal bovine serum (Invitrogen), $3.02 \mathrm{~g} / \mathrm{L}$ sodium bicarbonate (Sigma), $100 \mu \mathrm{g} / \mathrm{mL}$ streptomycin (Sigma) and $100 \mathrm{U} / \mathrm{mL}$ penicillin (Sigma). The cells were maintained at $37^{\circ} \mathrm{C}$ in humidified atmosphere with $5 \% \mathrm{CO}_{2}$ and $95 \%$ air. Adhesion, growth and morphological patterns were monitored by optical microscopy. Cells were regularly sub-cultured every two-three days and kept in culture for a maximum of three months.

Cell viability. The effect of T. albicans essential oil on macrophages viability $\left(0.3 \times 10^{6}\right.$ cells/well of 48 -well plates) was evaluated by MTT assay, as described by Zuzarte et al. ${ }^{59}$.

Nitric oxide production. The effect of the essential oil on NO production was evaluated by quantifying the concentration of its stable metabolites (nitrites) in macrophages culture supernatants, using the Griess colorimetric reagent, following the protocol described by Zuzarte et al. ${ }^{59}$.

Essential oil's mechanism of action in LPS-stimulated macrophages. Nitric oxide scavenging potential. The NO-scavenging potential of $T$. albicans essential oil was evaluated using S-nitroso-N-acetyl-DLpenicillamine (SNAP) reagent as a NO donor. The essential oil dilutions in culture medium were incubated with $300 \mu \mathrm{M}$ SNAP for $3 \mathrm{~h}$ in the dark at room temperature. An oil free control was included. Nitrite quantification was performed as described previously for nitric oxide production.

Expression of inducible nitric oxide synthase and cyclooxygenase-2. Western blot analyses were performed to evaluate the influence of the essential oil on the expression of inducible nitric oxide synthase (iNOS) and cyclooxygenase-2 (COX-2) on LPS-stimulated macrophages. Total cell lysates, protein concentration determination and western blot analysis were performed according to Zuzarte et al..$^{59}$. Membranes were revealed using a Typhoon FLA 9000 fluorescence reader (GE Healthcare, Chicago, IL, USA) and protein bands were measured by densitometric analysis using TotalLab TL120 (TotalLab, Newcastle, UK).

Statistical analyses. The results are expressed as mean \pm SEM of three independent experiments performed in duplicate. Differences between groups were calculated using one-way ANOVA followed by Dunnett's post hoc test or t-test, using GraphPad Prism v7.0a for Mac OS X. 


\section{Data availability}

The data that support the findings of this study are available upon request from the corresponding author, MZ.

Received: 29 May 2020; Accepted: 6 September 2020

Published online: 02 November 2020

\section{References}

1. Douglas, M., Heyes, J. \& Smallfield, B. Herbs, spices and essential oils: post-harvest operations in developing countries. UNIDO and FAO 61, 1-8 (2005).

2. EMA. (ed Committee on Herbal Medicinal Products (HMPC) European Medicines Agency) (Herba, Final Document of 12 November 2012 Doc. Ref. EMA/HMPC/342332/2013, 2007).

3. ESCOP. Thymi herba (thyme). ESCOP Monographs Second edition (2003).

4. Blumenthal, M. et al. The Complete German Commission E Monographs: Therapeutic Guide to Herbal Medicines (American Botanical Council/Integrative Medicine Communications, Austin, Newton, 1998).

5. WHO. WHO monographs on selected medicinal plants. Vol. 2 (World Health Organization, Geneva, 1999).

6. Stahl-Biskup, E. \& Venskutonis, R. Thyme. In Handbook of Herbs and Spices (ed. Peter, K. V.) 499-525 (Elsevier, Amsterdam, 2012 ).

7. WFO. Thymus albicans Hoffmanns and Link. https://www.worldfloraonline.org/taxon/wfo-0000323640 (2020).

8. Buira, A., Carapeto, A., \& Monteiro-Henriques, P. G. Thymus albicans. The IUCN Red List of Threatened Species 2017 e.T103496011A103496020 (2017).

9. Girón, V. et al. Geographical distribution of diploid and tetraploid cytotypes of Thymus sect. Mastichina (Lamiaceae) in the Iberian Peninsula, genome size and evolutionary implications. Folia Geobotanica 47, 441-460 (2012).

10. Morales Valverde, R. Taxonomía de los géneros Thymus (excluida de la sección serpyllum) y Thymbra en la Península Ibérica. (CSICReal Jardín Botánico (RJB), 1986).

11. Silva, A. et al. Plantas Aromáticas e Medicinais do Parque Natural da Serra da Estrela (CISE, Seia, 2011).

12. Blanca, G. et al. Libro rojo de la flora silvestre amenazada de Andalucía. I. Especies en peligro de extinción. (Junta de Andalucía, 1999).

13. Méndez-Tovar, I., Sponza, S., Asensio-S-Manzanera, M. \& Novak, J. Contribution of the main polyphenols of Thymus mastichina subsp. mastichina to its antioxidant properties. Ind. Crops Prod. 66, 291-298 (2015).

14. ECHA. Thyme, Thymus mastichina, ext. https://echa.europa.eu/registration-dossier/-/registered-dossier/27004/3/1/4 (2020).

15. ISO. Oil of Spanish wild marjoram (Thymus mastichina L.) (No. 4728), https://www.iso.org/standard/30436.html (2013).

16. Pina-Vaz, C. et al. Antifungal activity of Thymus oils and their major compounds. J. Eur. Acad. Dermatol. Venereol. 18, 73-78 (2004).

17. Fraternale, D., Giamperi, L. \& Ricci, D. Chemical composition and antifungal activity of essential oil obtained from in vitro plants of Thymus mastichina L. J. Essent. Oil Res. 15, 278-281 (2003).

18. Faleiro, M. et al. Antimicrobial activity of essential oils isolated from Portuguese endemic species of Thymus. Lett. Appl. Microbiol. 36, 35-40 (2003)

19. Ballester-Costa, C., Sendra, E., Fernández-López, J., Pérez-Álvarez, J. A. \& Viuda-Martos, M. Chemical composition and in vitro antibacterial properties of essential oils of four Thymus species from organic growth. Ind. Crops Prod. 50, 304-311 (2013).

20. Cutillas, A.-B., Carrasco, A., Martinez-Gutierrez, R., Tomas, V. \& Tudela, J. Thymus mastichina L. essential oils from Murcia (Spain): composition and antioxidant, antienzymatic and antimicrobial bioactivities. PLoS ONE 13, e0190790 (2018).

21. Aazza, S. et al. Antioxidant, anti-inflammatory and anti-hyperglycaemic activities of essential oils from Thymbra capitata, Thymus albicans, Thymus caespititius, Thymus carnosus, Thymus lotocephalus and Thymus mastichina from Portugal. Nat. Prod. Commun. 11, 1029-1038 (2016).

22. Miguel, G. et al. Composition and antioxidant activities of the essential oils of Thymus caespititius, Thymus camphoratus and Thymus mastichina. Food Chem. 86, 183-188 (2004).

23. Delgado, T. et al. Antioxidant activity of twenty wild Spanish Thymus mastichina L. populations and its relation with their chemical composition. LWT Food Sci. Technol. 57, 412-418 (2014).

24. Bentes, J. et al. Antioxidant activities of the essential oils and extracts of Portuguese Thymbra capitata and Thymus mastichina. Italian J. Food Sci. 21, 183-195 (2009).

25. Miguel, M. G. et al. Antioxidant and antiproliferative activities of the essential oils from Thymbra capitata and Thymus species grown in Portugal. Evid. Complement. Altern. Med. 2015, 851721. https://doi.org/10.1155/2015/851721 (2015).

26. Arantes, S. M. et al. Toxicological and pharmacological properties of essential oils of Calamintha nepeta, Origanum virens and Thymus mastichina of Alentejo (Portugal). Food Chem. Toxicol. 133, 110747 (2019).

27. Gordo, J. et al. Thymus mastichina: chemical constituents and their anti-cancer activity. Nat. Prod. Commun. 7, 1491-1494 (2012).

28. Faleiro, L., Miguel, G., Guerrero, C. \& Brito, J. In II WOCMAP Congress Medicinal and Aromatic Plants, Part 2: Pharmacognosy, Pharmacology, Phytomedicine, Toxicology 501. 45-48.

29. Miguel, M. G., Costa, L. A., Figueiredo, A. C., Barroso, J. G. \& Pedro, L. G. Assessment of the antioxidant ability of Thymus albicans, T. mastichina, T. camphoratus and T. carnosus essential oils by TBARS and micellar model systems. Nat. Prod. Commun. 2, 399-406 (2007).

30. Miguel, M. G. et al. Effect of the volatile constituents isolated from Thymus albicans, Th. mastichina, Th. carnosus and Thymbra capitata in sunflower oil. Food/Nahrung 47, 397-402 (2003).

31. GAFFI. Burden of common life-threatening fungal infections. https://www.gaffi.org/why/fungal-disease-frequency/ (2017).

32. Brown, G. D. et al. Hidden killers: human fungal infections. Sci. Transl. Med. 4, 165rv113 (2012).

33. Perlin, D. S., Rautemaa-Richardson, R. \& Alastruey-Izquierdo, A. The global problem of antifungal resistance: prevalence, mechanisms, and management. Lancet. Infect. Dis 17, e383-e392 (2017).

34. Romani, L. Immunity to fungal infections. Nat. Rev. Immunol. 11, 275-288 (2011).

35. Salgueiro, L. R. et al. Composition and variability of the essential oils of Thymus species from section Mastichina from Portugal. Biochem. Syst. Ecol. 25, 659-672 (1997).

36. Miguel, M. G., Duarte, F., Venâncio, F. \& Tavares, R. Composition of the essential oils from Portuguese Thymus albicans collected at different regions of Ria Formosa (Algarve). J. Essent. Oil Res. 16, 308-311 (2004).

37. Adam, K., Sivropoulou, A., Kokkini, S., Lanaras, T. \& Arsenakis, M. Antifungal activities of Origanum vulgare subsp. hirtum, Mentha spicata, Lavandula angustifolia, and Salvia fruticosa essential oils against human pathogenic fungi. J. Agric. Food Chem. 46, 1739-1745 (1998).

38. Salgueiro, L. R. et al. Antifungal activity of the essential oil of Thymus capitellatus against Candida, Aspergillus and dermatophyte strains. Flavour Fragr. J. 21, 749-753 (2006).

39. Hammer, K., Carson, C. \& Riley, T. Antifungal activity of the components of Melaleuca alternifolia (tea tree) oil. J. Appl. Microbiol. 95, 853-860 (2003).

40. Van Zyl, R. L., Seatlholo, S. T., Van Vuuren, S. F. \& Viljoen, A. Pharmacological interactions of essential oil constituents on the viability of microorganisms. Nat. Prod. Commun. 5, 1381-1386 (2010). 
41. Hendry, E., Worthington, T., Conway, B. R. \& Lambert, P. Antimicrobial efficacy of eucalyptus oil and 1,8-cineole alone and in combination with chlorhexidine digluconate against microorganisms grown in planktonic and biofilm cultures. J. Antimicrob. Chemother. 64, 1219-1225 (2009).

42. Şimşek, M. \& Duman, R. Investigation of effect of 1,8-cineole on antimicrobial activity of chlorhexidine gluconate. Pharmacogn. Res. 9, 234-237 (2017).

43. Lohse, M. B., Gulati, M., Johnson, A. D. \& Nobile, C. J. Development and regulation of single-and multi-species Candida albicans biofilms. Nat. Rev. Microbiol. 16, 19-31 (2018).

44. Vila, T. et al. Targeting Candida albicans filamentation for antifungal drug development. Virulence 8, 150-158 (2017).

45. Fanning, S. \& Mitchell, A. P. Fungal biofilms. PLoS Pathog. 8, e1002585 (2012).

46. Hsu, C.-C., Lai, W.-L., Chuang, K.-C., Lee, M.-H. \& Tsai, Y.-C. The inhibitory activity of linalool against the filamentous growth and biofilm formation in Candida albicans. Med. Mycol. 51, 473-482 (2013).

47. Zore, G. B., Thakre, A. D., Jadhav, S. \& Karuppayil, S. M. Terpenoids inhibit Candida albicans growth by affecting membrane integrity and arrest of cell cycle. Phytomedicine 18, 1181-1190 (2011).

48. Ramage, G. et al. Antifungal, cytotoxic, and immunomodulatory properties of tea tree oil and its derivative components: potential role in management of oral candidosis in cancer patients. Front. Microbiol. 3, 220 (2012).

49. Manoharan, R. K., Lee, J.-H. \& Lee, J. Antibiofilm and antihyphal activities of cedar leaf essential oil, camphor, and fenchone derivatives against Candida albicans. Front. Microbiol. 8, 1476 (2017).

50. Aktan, F. iNOS-mediated nitric oxide production and its regulation. Life Sci. 75, 639-653 (2004).

51. Zuzarte, M. et al. Antifungal and anti-inflammatory potential of Lavandula stoechas and Thymus herba-barona essential oils. Ind. Crops Prod. 44, 97-103 (2013).

52. Juergens, U. R. et al. Anti-inflammatory activity of 1,8-cineol (eucalyptol) in bronchial asthma: a double-blind placebo-controlled trial. Respir. Medi. 97, 250-256 (2003).

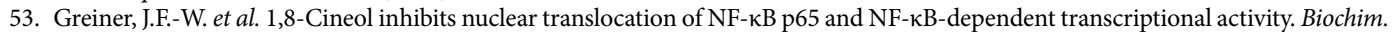
et Biophys. Acta Mol. Cell Res. 1833, 2866-2878 (2013).

54. Nogueira, M., Aquino, S., Junior, C. R. \& Spolidório, D. M. P. Terpinen-4-ol and alpha-terpineol (tea tree oil components) inhibit the production of IL-1 $\beta$, IL-6 and IL-10 on human macrophages. Inflamm. Res. 63, 769-778 (2014).

55. Peana, A. T., Marzocco, S., Popolo, A. \& Pinto, A. (-)-Linalool inhibits in vitro NO formation: probable involvement in the antinociceptive activity of this monoterpene compound. Life Sci. 78, 719-723 (2006).

56. Huo, M. et al. Anti-inflammatory effects of linalool in RAW 264.7 macrophages and lipopolysaccharide-induced lung injury model. J. Surg. Res. 180, e47-e54 (2013).

57. Ehrnhöfer-Ressler, M. M. et al. Identification of 1,8-cineole, borneol, camphor, and thujone as anti-inflammatory compounds in a Salvia officinalis L. infusion using human gingival fibroblasts. J. Agric. Food Chem. 61, 3451-3459 (2013).

58. Ocaña, A. \& Reglero, G. Effects of thyme extract oils (from Thymus vulgaris, Thymus zygis, and Thymus hyemalis) on cytokine production and gene expression of oxLDL-stimulated THP-1-macrophages. J. Obes. 2012, 104706 (2012).

59. Zuzarte, M. et al. New insights on the anti-inflammatory potential and safety profile of Thymus carnosus and Thymus camphoratus essential oils and their main compounds. J. Ethnopharmacol. 225, 10-17 (2018).

60. Council of Europe. In European Pharmacopoeia. Vol. 1 (2010).

61. Cavaleiro, C., Salgueiro, L., Miguel, M. G. \& Da Cunha, A. P. Analysis by gas chromatography-mass spectrometry of the volatile components of Teucrium lusitanicum and Teucrium algarbiensis. J. Chromatogr. A 1033, 187-190 (2004).

62. Van den Dool, H. \& Kratz, P. D. A generalization of the retention index system including linear temperature programmed gas-liquid partition chromatography. J. Chromatogr. 11, 463-471 (1963).

63. Adams, R. P. Identification of Essential Oil Components by Gas Chromatography/Quadrupole Mass Spectroscopy 4th edn. (Allured, Carol Stream, 2007).

64. Stein, S. E. Retention indices by NIST Mass Spec Data Center. In NIST Chemistry WebBook, NIST Standard Reference Database Number 69 (eds Linstrom, P. J. \& Mallard, W. G.) (National Institute of Standards and Technology, Gaithersburg, 2017).

65. McLafferty, F. W. Wiley Registry of Mass Spectral Data/NIST08 (Wiley, New York, 2009).

66. Alves-Silva, J. M. et al. New claims for wild carrot (Daucus carota subsp. carota) essential oil. Evid. Complement. Altern. Med. 2016, 9045196. https://doi.org/10.1155/2016/9045196 (2016).

\section{Acknowledgements}

We would like to thank Dr. Otília Vieira (CEDOC - Chronic Diseases Research Center) for kindly providing the mouse macrophage cell line (RAW 264.7).

\section{Author contributions}

M.R., M.Z., M.G. and J.S. performed experiments and analyzed data. C.C. performed GC and GC-MS analysis. M.R. made the literature review and wrote the first draft of the manuscript. M.Z. and M.C. reviewed the manuscript. L.S. supervised the work and reviewed the manuscript.

\section{Competing interests}

The authors declare no competing interests.

\section{Additional information}

Supplementary information is available for this paper at https://doi.org/10.1038/s41598-020-75244-W.

Correspondence and requests for materials should be addressed to M.Z.

Reprints and permissions information is available at www.nature.com/reprints.

Publisher's note Springer Nature remains neutral with regard to jurisdictional claims in published maps and institutional affiliations. 
(c) (i) Open Access This article is licensed under a Creative Commons Attribution 4.0 International cc) License, which permits use, sharing, adaptation, distribution and reproduction in any medium or format, as long as you give appropriate credit to the original author(s) and the source, provide a link to the Creative Commons licence, and indicate if changes were made. The images or other third party material in this article are included in the article's Creative Commons licence, unless indicated otherwise in a credit line to the material. If material is not included in the article's Creative Commons licence and your intended use is not permitted by statutory regulation or exceeds the permitted use, you will need to obtain permission directly from the copyright holder. To view a copy of this licence, visit http://creativecommons.org/licenses/by/4.0/.

(C) The Author(s) 2020 